\title{
In everlasting fight against academic procrastination: The roles of classroom engagement and internal locus of control
}

\author{
Yen Ling Hui, Kususanto Prihadi, Najiya I. Arif, Sam X.Y. Yap, Melissa J. Chua, John Chen, \\ Jia C. Chong, James L.H. Yeow \\ Department of Psychology, HELP University, Malaysia
}

\begin{tabular}{l}
\hline \hline Article Info \\
\hline Article history: \\
Received Jul 31, 2019 \\
Revised Oct 30, 2019 \\
Accepted Nov 23, 2019
\end{tabular}

Keywords:

Academic procrastination

Classroom engagement

Locus of control

\begin{abstract}
This study aims to test the hypothesis that classroom engagement mediates the relationship between students' internal locus of control and academic procrastination. As many as 302 students from a private university between 18 to 26 years of age were recruited to respond to Internal-External Locus of control Scale, Classroom Engagement Inventory, and Academic Procrastination scale. Bootstrapping analyses were conducted by utilizing PROCESS Macro model 4 in SPSS software, and the results showed that the mediator variable fully mediates the link between the predictor and outcome variables. In other words, the direct effect of internal locus of control on academic procrastination was no longer significant when controlling for classroom engagement. Further discussion, implications and suggestions were presented at the end of the article.
\end{abstract}

Copyright (c) 2019 Institute of Advanced Engineering and Science. All rights reserved.

\section{Corresponding Author:}

Kususanto Prihadi,

Department of Psychology,

HELP University,

No.2, Persiaran Cakerawala, Section U4, 401050 Shah Alam, Selangor, Malaysia.

Email: prihadi.k@help.edu.my

\section{INTRODUCTION}

Up until today, procrastination remains as a phenomenon that is not properly understood [1, 2]. Some of the concerns pertaining to procrastination is the negative consequences of it in daily lives; in worse case scenarios, it has become a malicious way of life for some individuals [3]. Procrastination predicts various aspects of our lives and has been more commonly studied in higher education settings [4], where students tend to complete assignments only at the very last minute prior to their deadlines [5]. Contextually, the term academic procrastination refers to the intentional delay of academic-related tasks in spite of anticipating negative consequences such as poorer academic performance and psychological wellbeing [3]. Academic procrastination among undergraduate students happens on a day to day basis, and it is reported to be problematic as it reduces productivity [4]. It is also viewed as a result of irrational thought processes in relation to academic performance, such as being unable to fulfil their daily demands as students [6].

It has been reported that internal factors contributed to procrastination behaviour [5] such as learned helplessness [7], self-esteem [8], self-efficacy [9, 10], negative self-appraisals on personal responsibility and ability in completing [11], as well as locus of control [6, 12-14]. Interrelationship among these internal factors predicts academic procrastination tendency among students; nevertheless, it is imperative to study factors that educators can alter in order to reduce the tendency of academic procrastination. In the context of this current study, the role of classroom engagement in explaining the link between students' locus of control and their procrastination tendency was investigated, because educators can be trained to improve students' classroom engagement [15]. In other words, education stakeholders should be able to focus on chanelling their effort to improve the classroom engagement when it is proven to contribute to the reduction of procrastination tendency. 
Almost a decade ago, another study in the context of Malaysian education setting reported that locus of control mediates the link between students' perception of teachers' expectancy on their self-esteem [16]. In other words, they indicated that the way the students credit themselves for their events, can explain the link between their perception of teachers' expectancy and the way they value themselves. Another study in Albania established that locus of control, together with other personality factors, played important role in predicting procrastination [17]. It is worth to note that self-esteem was also reported as a strong predictor of procrastination [8]. In line with that, another study in Malaysian context reported that when students believe that they are in control of their events (possess high level of internal locus of control), the less likely they will procrastinate doing their tasks although they believe that they are incapable of finishing the task properly [13]. Other than that, external factors such as the existence of a well-structured academic goal predicts the decrease of academic procrastination [2] and a recent study done in a mathematics class $\left(8^{\text {th }}\right.$ and $10^{\text {th }}$ grade students) showed that intrinsic motivation and effort are predicted by goal structures that aim to promote autonomy and personal achievement [18]; whereby students tend to cope better with their academic related tasks when they set goals [19]. This is supported by the theory of locus of control [20]. In contrast, when students have external locus of control, such as a sense of blame towards others, they tend to escape the anticipated failure by engaging in academic procrastination [11]. The aforementioned studies showed that locus of control is a robust predictor that explained the contribution of external or internal factors on academic procrastination. Thus, it leads to a question whether the predicting power of locus of control on academic procrastination can be mediated by any other external factors. It is noteworthy to answer such 1 'z+as question because the task of educators to improve students' internal locus of control in order to reduce their procrastination habit is very complicated, since locus of control is either inborn or developed at a very young age.

Past studies in the area of procrastination suggested that the students' social environment (such as peers and teachers) might predict their procrastination behaviour [21, 3]. Furthermore, classroom engagement is a predictor of many desirable academic traits. For instance, a study among 687 college students in the Philippines reported that classroom engagement significantly and positively impacts college experience (learning experience in college), which subsequently affects their academic performance [15]. In line with that, a meta-analysis on classroom engagement and achievement based on 92 studies published from 1990 to 2011 with a total of 129,423 responses obtained from primary and secondary school students reported a general consensus that positive teacher student relationship is associated with higher school engagement and academic achievement [22]. It can be concluded that when students perceive their environment in a positive light, whereby they particularly feel supported and cared for by their educators, will tend to have higher school engagement and academic achievement.

Similar findings on the importance of having a positive teacher-student relationship had been reported over the past few decades; for example, a study done among children between 7 and 12 years old found that students tend to have a more positive attitude towards learning, such as taking more initiatives in their learning related tasks when the teachers are supportive and involved in their learning related activities [23], and a longitudinal study on 2079 high school students across 18 Australian schools, which reported that across various school subjects, the need for improved relationships between students and teachers was highlighted whereby greater teacher-student relationship is positively correlated with improved academic involvement [24]. In short, putting in effort to enhance teacher-student relationships might lead to greater academic involvement by the students.

Moreover, it seems that peer relationship in classroom settings refers to how well students can relate to or interact with their classmates, which has been found to be a factor of the students' overall learning experience and academic performance [25]. This is further supported by a recent meta-analysis which revealed that there is a significant relationship between student engagement (students' level of involvement in learning related tasks) and academic performance, whereby greater student engagement is associated with greater academic performance [26]. Nevertheless, the terms teacher-student relationship, peer relatedness, coaching relationship, and student engagement in the context of academic learning seem to share certain similarities, whereby they can all be related to the interactions and relationships in their learning environment. Briefly, another similar concept is the "coaching relationship", whereby the role of a coach is to facilitate the coachee's learning experience, enabling them to be more autonomous and self-efficacious, and ultimately reduce procrastination behaviour [27]. This reflects the idea that educators have an important role in fostering a more effective and productive learning environment for students [28], which can be expected to reduce academic procrastination in the long run. Apart from that, another study done among 200 adolescents in the Rivers State of Nigeria, locus of control has been linked to learned helplessness, which ultimately contributes to academic challenges faced by the students [29]. The ex-post facto study further explained that the more the environment is perceived as uncontrollable, the easier it is for them to view failure as an inevitable outcome. These students are more likely to experience learned helplessness, resulting in 
problematic behaviours that contributes to their academic challenges [29]. Similarly, an ex-post facto study on academic procrastination was conducted with a sample size of 107 students from an Islamic educational institution [6]. The study found that students with high internal locus of control believe that their effort determines the outcome of their success or failures, and their belief enables them to feel more confident about themselves, which explains their higher levels of effort and ability to accomplish tasks on time.

The aforementioned studies reflected the idea that classroom engagement can have a strong influence on students' overall learning experience, includig academic procrastination. It has also been noted that research in the area of student engagement is insufficient, specifically due to the lack of studies on classroom engagement level [30]. Given that internal locus of control plays a prominent role on the students' attitude towards their academics [6], it could be that students with high internal locus of control tend to be more engaged in their classrooms, and take more initiatives in learning, which could explain their decreased tendency to procrastinate. Hence, it is hypothesized that classroom engagement will mediate the relationship between internal locus of control and academic procrastination, whereby high internal locus of control will predict high classroom engagement, which subsequently predicts low academic procrastination. For the purpose of this paper, the term classroom engagement will be used to refer to the level of students' involvement in classroom learning related activities [31], as well as social interactions in classroom settings. In order for educators to foster more classroom engagement and interest in learning, it was suggested that the lesson plans, or activities should be structured such that it encourages involvement of the students' relevance (how well the students can relate to the topic), responsibility (students can learn autonomously), and reality (applicable to real-life problem-solving skills) [32].

Researchers in the area of education, especially in the educational setting similar or identical to Malaysia, would find this current study relevant as it sheds light on the importance of classroom engagement on students' attitude towards learning related tasks. Moreover, the knowledge obtained from such studies indicated the need to enhance training programmes for the educators and other staff members in the educational settings to improve the students' social environment, including the level of classroom engagement [24].

\section{RESEARCH METHOD}

Participants of this current study consisted of 302 undergraduate students from a private university in Malaysia (237 women, 64 men, and one preferred to be not identified by gender). Informed consent form and demographics questionnaire were provided before the questionnaire, whereby clicking next to proceed to the questionnaire indicated that the participants have read and agreed to give informed consent. The participants' age ranged from 18 to 26 years old, whereby 148 participants were 18-20 years old, 147 participants were 21-23 years old, and only 7 participants were 24-26 years old. A total of 280 participants majored in social science, 10 participants majored in science, and 9 participants majored in arts. Most of them participated voluntarily and acknowledged that no compensation was given for their participation; however, those who are psychology undergraduate students of a Malaysian private university were compensated with $0.25 \%$ extra course credits for their participation.

A demographic questionnaire was used to collect demographic information which were age, gender, which major they were studying in, and the country they were studying in. Rotter Internal-External Locus of control Scale was used to measure participants' level of ILOC. The scale consisted of 29 items, whereby each item had two statements. Among the items were "28a. What happens to me is my own doing, b. Sometimes I feel that I don't have enough control over the direction my life is taking", and " $29 \mathrm{a}$. Most of the time I can't understand why politicians behave the way they do, b. In the long run people are responsible for bad government on a national as well as a local level". The instruction for this scale required participants to select the statement ( $\mathrm{a}$ or b) they agreed with the most. Items number 1, 8, 14, 19, 24, and 27 were fillers. This scale had high reliability as the Cronbach alpha was .74 (Lange \& Tiggemann, 1981). ILOC was measured based on the total score of the scale, whereby a higher total score indicated higher ILOC.

The Classroom Engagement Inventory (Wang et al., 2014) was used to measure participants' level of classroom engagement. The scale consisted of 24 items which were measured on a 5-point likert scale, whereby 1 = never, 2 = hardly ever, $3=$ monthly, $4=$ weekly, and $5=$ each day of class. The participants were asked to rate the items based on how they usually feel during class time. The items were statements such as "11. I don't want to stop working at the end of class" and " 12 . I actively participate in class discussions". Items 22, 23, and 24 were reverse scored items, whereby a higher score for these items indicate lower levels of classroom engagement. Examples of reverse scored items included " 23 . I let my mind wander" and "24. I just pretend like I'm working". The reliability test showed a moderate to moderately high level of reliability, whereby the Cronbach alpha for the items of the inventory ranged from .62 to .86 (Wang 
et al., 2014). Classroom engagement was measured based on the total score of the scale, whereby a higher total score indicates higher levels of classroom engagement.

The Academic Procrastination scale (Lay, 1986) was used to measure academic procrastination. The scale consisted of 20 items which were measured on a 5-point likert scale, whereby $1=$ extremely uncharacteristic and $5=$ extremely characteristic. The participants were asked to rate each item in accordance to how closely it represents them. Some examples of the items included "17. I usually buy an essential item at the last minute" and " 19 . I am continually saying I'll do it tomorrow". Items 3, 4, 6, 8, 11, 13, 14, 15, 18, and 20 were reverse scored items, whereby higher scores for these items indicated less academic procrastination. The reverse scored items were such as " 3 . When I am finished with a library book, I return it right away regardless of the date it is due" and " 4 . When it is time to get out of bed in the morning, I most often get right out of bed". The scale had high overall internal reliability as the Cronbach alpha was .94 (McCloskey \& Scielzo, 2015). Academic procrastination was measured based on the total score of the scale, whereby a higher total score indicated more academic procrastination.

\section{RESULTS AND DISCUSSION}

Process macros Model 4 in SPSS 20 software was utilized in order to conduct bootstrap analyses to all the paths and the results are compiled in the Table 1.

Table 1. Results of the mediation analyses of each path

\begin{tabular}{lllll}
\hline path $\mathrm{a}$ & $\mathrm{path} \mathrm{b}$ & $\mathrm{path} \mathrm{c}$ & $\mathrm{path} \mathrm{ab}$ & $\mathrm{path} \mathrm{c}^{\prime}$ \\
\hline $\mathrm{F}(1,3)=12.56$ & $\mathrm{~F}(2,299)=18.18$ & $\mathrm{~F}(1,300)=5.80$ & $(\mathrm{~b}=-1.45)$ & $\mathrm{F}(2,299)=18.18$ \\
$\mathrm{p}<.001$, & $\mathrm{p}<.001$, & $\mathrm{p}=.017$, & $\mathrm{BCaCI}[-3.37,-.18]$ & $\mathrm{p}=.171$, \\
$\mathrm{R}^{2}=.04$ & $\mathrm{R}^{2}=.11$ & $\mathrm{R}^{2}=.02$ & Does not contain zero & $\mathrm{R}^{2}=.11$ \\
$\mathrm{~b}=.66$, & Controlled for ILOC & $\mathrm{b}=.-45$, & & Controlled for ILOC \\
$\mathrm{t}(3)=-.3 .54, \mathrm{p}<.001$ & $\mathrm{~b}=-.25$, & $\mathrm{t}(300)=-2.41$, & & $\mathrm{b}=.15$, \\
& $\mathrm{t}(299)=-1.36$, & $\mathrm{p}=.017$ & & $\mathrm{t}(299)=-.250$, \\
& $\mathrm{p}=.171$ & & & $\mathrm{p}=.171$ \\
& & & \\
\hline
\end{tabular}

Table 1 depicts the interrelationship among variables. Path $a$ shows that ILOC has significant positive effect on classroom engagement $[F(1,3)=12.56, p<.001]$. In other words, the predictor has significant positive effect on the mediator $(b=.66)$; which means that one-point increment of the ILOC of a participant led to the 0.66 points increment of classroom engagement. In path $b$, it was shown that classroom engagement as a model (interaction between ILOC and classroom engagement) significantly predicts the decrease academic procrastination among the participants $[F(2,299)=18.18, p<.001]$; one point increment of the model of classroom engagement drops academic procrastination by 0.25 points $(b=-.25)$. Furthermore, path $c$ shows that ILOC significantly predicts AP $[F(1,300)=5.80 ; \mathrm{p}=.017]$, and the contribution is negative $(b=-.45)$; which means that when the level of the internal locus of control of the participants is increased by one point, their academic procrastination will be decreased by 0.45 points. Finally, the bias-corrected bootstrapped confidence interval does not contain zero $\mathrm{BCaCI}[-3.37$, -.18], which means that classroom engagement fully mediates the link between internal locus of control and academic procrastination. Supporting that, path $c^{\prime}$ shows that ILOC did not significantly predict AP $[F(2,299)=18.18 ; p=.171]$ when controlling for CE. In other words, internal locus of control does not predict academic procrastination without being mediated by classroom engagement.

Another finding of the current analysis was that the contribution of classroom engagement on academic procrastination (path $b$ ) is not significant when controlling for internal locus of control $[b=-.25$, $t(299)=-1.36, p=.171]$. The fact that classroom engagement does not significantly predict academic procrastination without its interaction with internal locus of control will be discussed below.

The hypothesis was supported, classroom engagement mediated the relationship between internal locus of control and academic procrastination, whereby high ILOC predicted high classroom engagement, which subsequently predicted low academic procrastination. This reflects that classroom engagement explained the relationship between ILOC and academic procrastination, whereby high ILOC predicts high classroom engagement, which subsequently decreased academic procrastination.

Findings of this study enrich the previous studies in the similar context of Malaysian educational settings. When Prihadi et al. [13] reported the mediation role of ILOC on the link between learned helplessness and academic procrastination, there was still a question whether ILOC is a major significant factor that decrease academic procrastination, up to an extent where it can alter the influence of learned 
helplessness. This current study indicates that ILOC, despite its significant prediction, is also mediated by classroom engagement; in other words, students with high internal locus of control still need to be engaged in their classroom environment in order to reduce their procrastination behaviour.

As reported by Nordby et al. [21], and Steel and Klingsieck [3], classroom engagement is a significant factor to reduce academic procrastination. The path $c^{\prime}$ analysis of this current study illustrated that ILOC can only significantly predict the decrease of procrastination when the students show classroom engagement; without classroom engagement, ILOC does not significantly predict the decrease of procrastination.

The current findings strongly suggest that the need to improve students' attitude towards learning environment is higher than making sure all the students believe that they are in control over their events. Additionally, the current study also suggests that the role of educators can potentially function as a preventive measure to reduce academic procrastination tendencies, by increasing the classroom engagement $[21,6]$. In other words, educators can actively enhance students' attitude towards learning by guiding and equipping them with adaptive coping mechanisms they need especially when they feel defeated in their academic pursuits [29] in order to decrease the procrastination behaviour.

Findings of this current study also suggest the possibility to reduce procrastination among students who undermine personal responsibility and ability in completing their tasks [11] by making classroom environment more appealing to them. In turn, students who feel capable of handling situations are more likely to take ownership and strive (high internal locus of control), therefore procrastinate less when their classroom engagement is improved. As suggested by the findings of this current study, active effort of educators to improve classroom engagement might help to discourage maladaptive behaviours such as engaging in academic procrastination.

Apart from that, one of the strategies to reduce academic procrastination is by setting specific goals and plans to achieve targeted goals $[11,18,2]$ might also be paired with the improvement of classroom engagement, because the goal-setting activities will enhance internal locus of control in the form of sense of responsibility; therefore, the improvement of classroom engagement will decrease the likelihood of procrastination among students who have set their goals. In other words, educators could increase classroom engagement by getting students to set goals and plans to maintain their goal-directed behaviour. As the current findings have shown that internal locus of control and classroom engagement have a significant positive relationship, and that efforts on increasing classroom engagement will in turn increase internal locus of control and subsequently reduce academic procrastination. Briefly, the SMART intervention is recommended as a goal setting strategy modified for the purpose of reducing academic procrastination among college students, and has been found to be effective [33]).

The secondary finding of this current study that the mediator variable does not significantly predict the outcome variable when controlling for the predictor variable indicated that classroom engagement alone does not contribute to academic procrastination without the existence of internal locus of control. In other words, students who are positively engaged in their classroom (having positive teacher-student relationships, positive peer environments, etc.) might still engage in academic procrastination behavior if they do not believe that they are in control of their own events (having internal locus of control) and vice versa. This finding implies that the link between internal locus of control and academic procrastination such as the ones established by Prihadi et al. [13] or Dervishaliaj and Xhelili [17] might show different results when the variable of classroom engagement was involved in their studies.

\section{CONCLUSION}

Several limitations have been identified and should be acknowledged as well. Firstly, some of the participants may have been motivated to participate simply for the extra credits and may not have filled in the questionnaires carefully, and thereby reducing the accuracy of their responses. Secondly, the context of environmental factor in this study was limited to classroom engagement only. Third, majority of the sample majored in social science, which could result in cohort effect. Thereby, it is suggested for future studies to consider examining other factors such as parental and peer influence on academic procrastination, because learning is not limited to classroom settings only. Another consideration for future studies is to employ the cross-sectional method by having an equal number of undergraduate students across various majors such as engineering, law, and medicine. This would enable future studies to take into account the nature of their courses, which may influence the nature of their classroom settings and learning related tasks. Another suggestion based on the last finding of this current study is to replicate previous studies that involves locus of control and examine classroom engagement as the mediation factor in order to get further knowledge to determine whether there is an interaction effect between locus of control and classroom engagement in predicting academic procrastination.

In everlasting fight against academic procrastination: The roles of classroom engagement ... (Yen Ling Hui) 
The practical implication of this study is focused on the role of educators, whereby efforts such as providing personalized feedback and advice can promote autonomy, which will hopefully reduce academic procrastination. In conclusion, this study is in line with past findings which highlights the need for a more effective approach to foster classroom engagement because it plays a crucial role in explaining the relationship between internal locus of control and academic procrastination.

\section{ACKNOWLEDGEMENTS}

This study is a part of a research funded by Internal Research Grant Scheme No. 17-12-020 by Research Management Center, HELP University Malaysia.

\section{REFERENCES}

[1] V. K. Balaji and R. Indradevi, "Relatonship of academic procrastination and consideration of future consequences: An empirical study among university students," Global Management Review, vol. 11(1), pp. 43-56, 2017.

[2] S. Tripathi, A. Kochar and P. Dara, "Role of self-efficacy and hope in academic procrastination among undergraduate students," Indian Journal of Positive Psychology, vol. 6(4), pp. 376, 2015

[3] P. Steel and K. Klingsieck, "Academic procrastination: Psychological antecedents revisited," Australian Psychologist, vol. 51(1), pp. 36-46, 2016.

[4] M. Khan, H. N. S. Arif and S. Muneer, "Academic procrastination among male and female university and college students," FWU Journal of Social Sciences, vol. 8(2), p. 65, 2014.

[5] M. Philips, "Does locus of control task interest have an effect on procrastination?," The Huron University College Journal of Learning and Motivation, vol. 50(1), p. 8, 2012.

[6] J. Batubara and A. Asriatuzzeky, "Contribution locus of control and self esteem to student academic procrastination (A Study at Department of Islamic Guidance And Counseling, IAIN IB Padang)," GUIDENA: Jurnal Ilmu Pendidikan, Psikologi, Bimbingan dan Konseling, vol. 7(1), pp. 4-62, 2017.

[7] D. Lemoine, "The process of self-discovery: Learned helplessness, self-efficacy, and endogenous overoptimism," 1 7 2016. [Online]. Available: https://ssrn.com/abstract=2768511.

[8] J. Athulya, P. M. Sudhir and M. Philip, "Procrastination, perfectionism, coping and their relation to distress and selfesteem in college students," Journal of the Indian Academy of Applied Psychology, vol. 42(1), pp. 82-91, 2016.

[9] R. M. Klassen, L. L. Krawchuk and S. Rajani, "Academic procrastination of undergraduates: Low self-efficacy to self-regulate predicts higher levels of procrastination.," Contemporary Educational Psychology, vol. 33(4), pp. 915-931., 2008.

[10] K. Wäschle, A. Allgaier, A. Lachner, S. Fink and M. Nückles, "Procrastination and self-efficacy: Tracing vicious and virtuous circles in self-regulated learning," Learning and instruction, vol. 29, pp. 103-114, 2014.

[11] H. Mohaghegi and S. Sadhegi, "The relation between educational neglect and cognitive incompatibility and learned helplessness," International Journal of Sport Culture and Science, vol. 5(1), pp. 35-45, 2017.

[12] E. W. M. Au, "Locus of control, self-efficacy, and the mediating effect of outcome control: Predicting course-level and global outcomes in an academic context," Anxiety, Stress, \& Coping, vol. 28(4), pp. 425-444, 2015.

[13] K. Prihadi, C. Y. Tan, R. T. Tan, P. L. Yong, J. H. Yong, S. Tinagaran and J. L. Yeow, "Procrastination and learnedhelplessness among university students: The mediation effect of internal locus of control," Electronic Journal of Research in Educational Psychology, vol. 46(1)6, pp. 579-595, 2018.

[14] M. Richardson, C. Abraham and R. Bond, "Psychological correlates of university students' academic performance: A systematic review and meta-analysis," Psychological Bulletin, vol. 138(2), pp. 353-387, 2012.

[15] J. T. Amora, M. S. A. Ochoco and R. C. R. Anicete, "Student engagement and college experience as mediators of the relationship between institutional support and academic performance," Digital Journal of Lasallian Research, vol. 12, pp. 15-30, 2016.

[16] K. Prihadi, N. I. Hairul and J. Hazri, "Mediation effect of locus of control on the causal relationship between students' perceived teachers' expectancy and self-esteem," Electronic Journal of Research in Educational Psychology, vol. 10(27), pp. 713-736, 2012.

[17] E. Dervishaliaj and G. Xhelili, "Academic procrastination and locus of control in graduate students," in The 2nd International Conference on Research and Education Challenges towards the Future (ICRAE 2014), 2014.

[18] E. Skaalvik, R. Federici, A. Wigfield and T. Tangen, "Students' perceptions of mathematics classroom goal structures: Implications for perceived task values and study behavior," Social Psychology of Education, vol. 20(3), pp. 543-563, 2017.

[19] M. Kandemir, "Reasons of academic procrastination: Self- regulation, academic self-efficacy, life satisfaction and demographics variables," Social and Behavioral Sciences, vol. 152, pp. 188-193, 2014

[20] J. B. Rotter, Social learning and clinical psychology, 1954.

[21] K. Nordby, K. B. Klingsieck and F. Svartdal, "Do procrastination-friendly environments make students delay unnecessarily?," Social Psychology of Education, vol. 20, pp. 491-512, 2017.

[22] D. Roorda, H. M. Y. Koomen, J. L. Spilt and F. J. Oort, "The influence of affective teacher-student relationships on students' school engagement and achievement: A meta-analytic approach," Review of Educational Research, pp. 1-60, 2011. 
[23] E. A. Skinner and M. J. Belmont, "Motivation in the classroom: Reciprocal effects of teacher behaviour and student engagement across the school year," Journal of Educational Psychology, vol. 85(4), pp. 571-581, 1993.

[24] Martin and R. Collie, "Teacher-student relationships and students' engagement in high school: Does the number of negative and positive relationships with teachers matter?," Journal of Educational Psychology, vol. 111(5), pp. 861, 2019.

[25] Mikami, E. Ruzek, C. Hafen, A. Gregory and J. Allen, "Perceptions of relatedness with classroom peers promote adolescents' behavioral engagement and achievement in secondary school," Journal of Youth \& Adolescence, vol. 46(11), pp. 2341-2354, 2017.

[26] H. Lei, Y. Cui and W. Zhou, "Relationships between student engagement and academic achievement: A metaanalysis," Social Behavior \& Personality: An International Journal, vol. 46(3), pp. 517-528, 2018.

[27] Sims, "Self-regulation coaching to alleviate student procrastination: Addressing the likeability of studying behaviours," International Coaching Psychology Review, vol. 9(2), pp. 147-164, 2014

[28] Kausar, A. I. Kiyani and Q. Suleman, "Effect of classroom environment on the academic achievement of secondary school students in the subject of Pakistan studies at secondary level in Rawalpindi District, Pakistan," Journal of Education and Practice, vol. 8(4), 2017.

[29] R. Ekechukwu and B. C. Isiguzo, "Psychological factors associated with learned helplessness among adolescents in rivers state," European Journal of Research and Reflection in Educational Sciences, vol. 3(4), pp. 89-96, 2015.

[30] Z. Wang, C. Bergin and D. A. Bergin, "Measuring engagement in fourth to twelfth grade classrooms: The classroom engagement inventory," School Psychology Quarterly, pp. 1-19, 2014.

[31] E. A. Skinner, T. A. Kindermann and C. A. Furrer, "A motivational perspective on engagement and disaffection conceptualization and assessment of children's behavioral and emotional participation in academic activities in the classroom," Educational and Psychological Measurement, pp. 1-33, 2008.

[32] G. Claxton, "Expanding young people's capacity to learn," British Journal of Educational Studies, vol. 55(2), pp. 1-20, 2007.

[33] J. F. Muñoz-Olano and C. Hurtado-Parrado, "Original article: Effects of goal clarification on impulsivity and academic procrastination of college students," Revista Latinoamericana de Psicología, vol. 49, pp. 173-181, 2017. 